\title{
PODE A LITERATURA LATINO-AMERICANA NOS ENSINAR A RESPEITAR OS IMIGRANTES?
}

\author{
CAN LATIN AMERICAN LITERATURE \\ TEACH US TO RESPECT IMMIGRANTS?
}

\author{
José Veranildo Lopes da Costa Junior* \\ Ruan Fellipe Munhoz ${ }^{* *}$
}

\begin{abstract}
Resumo: O presente ensaio apresenta uma discussão sobre os interstícios entre literatura e imigração. Para tanto, nossas problematizações consideram as especificidades da América Latina como um espaço em conflito que ilustra os trânsitos territoriais de povos fronteiriços na contemporaneidade. Dando importância a uma série de eventos recentes, que ressaltam a complexidade da imigração, através da violação dos direitos humanos de imigrantes de diversos países, propomos uma reflexão sobre a seguinte pergunta norteadora: Pode a literatura latino-americana nos ensinar a respeitar o outro? A partir desta indagação, analisaremos dois poemas não-canônicos sobre a experiência do imigrante em terras estranhas, ressaltando a importância do acesso e, por consequência, da leitura de literatura em espaços diversos, como objeto que nos permite conhecer a nossa própria história e nos humanizar. Quanto à fundamentação teórica, dialogamos, sobretudo, com textos de Antonio Candido (2004), Regina Dalcastagnè (2012; 2018) e Marcia Tiburi (2018).
\end{abstract}

Palavras-chave: Literatura. Imigração. América Latina.

Abstract: The present essay shows a discussion about the interstices between literature and immigration. To this end, our problematizations consider the specificities of Latin America as a space in conflict that illustrates territorial transits of border peoples in contemporaneity. Emphasizing a series of recent events, which highlight the complexity of immigration, by means of human rights violation of immigrants in many countries, we propose the following guiding question: Can Latin American literature teach us to respect the other? From this inquiry, we will analyze two non-canonical poems concerning the experience of the immigrant in strange lands, pointing out the importance of having access and, consequently, reading literature in different spaces, as an object that allows us to know our own history and humanize ourselves. Regarding theoretical foundation, we especially dialogue with texts from Antonio Candido (2004), Regina Dalcastagnè (2012; 2018) and Marcia Tiburi (2018).

Keywords: Literature. Immigration. Latin America.

\section{Localizando a problemática}

Regressou a si

Estrangeiro

Sem bilhete de volta

Sem malas ou pesos

No bolso

Trouxe o mundo

Revirado ao avesso

Cheio de recomeço

O estrangeiro, Evangley de Queiroz.

\footnotetext{
*Professor do Departamento de Letras Estrangeiras da Universidade do Estado do Rio Grande do Norte. jveranildo@hotmail.com

** Universidade Estadual de Maringá. Doutorando em Estudos Literários pela Universidade Estadual de Maringá. ruan_munhoz@hotmail.com
} 
A representação da imigração na literatura é uma temática relativamente bem explorada por escritoras e escritores do mundo ocidental. O trânsito territorial, que gera a discussão sobre deslocamentos e imigração, faz parte, inclusive, da própria história da América Latina. Poderíamos citar como exemplos as narrativas de viagens escritas durante o processo de colonização latino-americana, que trazem a perspectiva europeia sobre o novo continente. Se pensarmos mais contemporaneamente, encontramos em Clarice Lispector outro exemplo de deslocamento e de imigração territorial. Em Cuba, Reinaldo Arenas também problematiza as questões de imigração através da ótica do exílio. Mais recentemente, o escritor brasileiro Julián Fuks, filho de argentinos, conquistou visibilidade no mercado editorial com a publicação de $A$ resistência (2015), romance que retrata a história de uma família argentina que veio ao Brasil fugindo da ditadura e da repressão em sua terra de origem.

Os poucos exemplos citados anteriormente são importantes para ilustrar o fato de que a literatura ocidental está permeada por questões concernentes à imigração, com narrativas de vida particulares e específicas, em contextos e conjunturas múltiplas. Entretanto, o estranho (associado ao estrangeiro, na acepção lexical da palavra), mesmo ocupando um espaço de representação na literatura e nos estudos literários, ainda é um símbolo controverso, pois desencadeia conflitos identitários, intolerância em relação à sua nacionalidade e discussão a respeito do seu lugar de fala.

Trazendo a questão para a realidade jornalística, mais especificamente ao fato marcante ocorrido no ano de 2015, entramos em contato com as notícias que retratavam a morte de Aylan Kurdi, o garoto sírio-curdo de três anos que se afogou no Mar Mediterrâneo quando sua família tentava chegar à Grécia. A fotografia em que o policial turco recolhe o corpo do menino ganhou destaque nas redes sociais e tornou-se um dos assuntos mais comentados no mundo ${ }^{\dagger}$.

Em Gaza, uma escultura foi construída em uma praia, como forma de homenagem ao garoto morto, representando, de forma enfática, a difícil situação dos imigrantes e dos refugiados do Oriente Médio que se deslocam até o continente europeu na tentativa de sobreviver aos atentados registrados naqueles países:

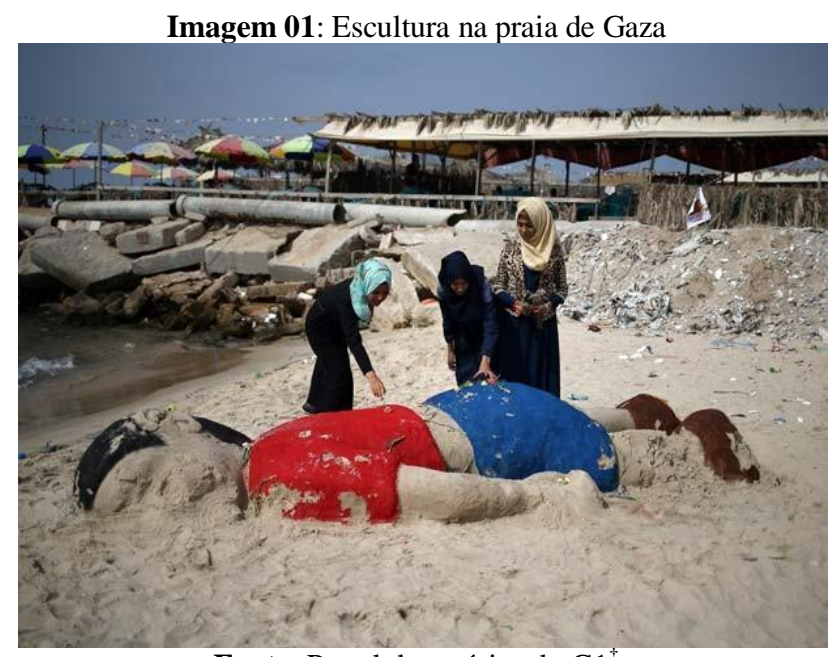

Fonte: Portal de notícias do G1*

\footnotetext{
${ }^{\dagger}$ Disponível em: http://g1.globo.com/mundo/noticia/2015/09/foto-chocante-de-menino-morto-vira-simbolo-da-crisemigratoria-europeia.html. Acesso em: 15 de dezembro de 2018.

* Disponível em: http://g1.globo.com/mundo/noticia/2015/09/escultura-de-areia-em-gaza-lembra-menino-sirioafogado.html. Acesso em: 15 de dezembro de 2018.
} 
Em um primeiro olhar, a escultura acima nos causa tristeza e indignação, afinal de contas podemos nos perguntar: como permitimos que o horror aconteça? $\mathrm{Ou}$, então, nos questionar: o ser humano é capaz de enxergar a humanidade do outro? Esse exemplo, traumático, mostra que precisamos evoluir enquanto sociedade, pois somos movidos por sentimentos de egoísmo e de falta de amor ao próximo. Entretanto, para que possamos discutir os próximos exemplos, é preciso recordar que o caso do menino Aylan Kurdi sensibilizou a sociedade brasileira, a qual qualificou, nas redes sociais, o episódio como traumático, triste e revoltante.

Embora pareça distante do que queremos discutir neste texto, é preciso considerar também que, em 2016, o Brasil viveu um importante evento histórico: o processo que levou à destituição da Presidenta Dilma Rousseff. Como desdobramento do referido Impeachment, o então deputado Jair Bolsonaro ganhou ainda mais notoriedade no cenário nacional. Representante de um discurso machista-misóginoracista-homofóbico-fascista, Bolsonaro chegou a afirmar, em entrevista para o Jornal Opção, de Goiás, um ano antes do Golpe, que haitianos, senegaleses, iranianos, bolivianos e sírios são "a escória do mundo" .

Com essa declaração, Jair Bolsonaro ganhou mais um adjetivo para o seu histórico discursivo: xenofóbico, ou seja, aquele que tem desconfiança, temor e antipatia por pessoas estranhas, estrangeiras. Além disso, Bolsonaro é um notório admirador do presidente estadunidense, Donald Trump, que prometeu, dentre outras ações, construir um muro que divide os Estados Unidos do México e, consequentemente, da América Latina.

Ainda em 2015, o Centro de Investigação e Docência em Economia do México, em colaboração com universidades latino-americanas, através do projeto The Americas and the World: Public Opinion and Foreign Policy, divulgou alguns números de uma pesquisa realizada na América Latina. Segundo o estudo, apenas $4 \%$ dos brasileiros se definem como latino-americanos, porcentagem que pode ser explicada pelo nosso processo de colonização que impede de nos reconhecermos como latinoamericanos $^{* *}$.

Ainda de acordo com a pesquisa citada, os brasileiros se consideram o melhor representante da América Latina no Conselho de Segurança da Organização das Nações Unidas, mesmo que o livre trânsito de latino-americanos pelas fronteiras do nosso país seja rejeitado pela maioria dos entrevistados. Com esses dados, podemos notar que o brasileiro, além de não se reconhecer como parte da identidade latino-americana, age, em muitas situações, de forma paradoxal.

Em síntese, é preciso salientar que somos um dos países que mais realiza transações comerciais no exterior. Também nos destacamos quando o assunto é o trânsito e a moradia em países estrangeiros. Contudo, apesar de nos orgulharmos da posição estratégica em que estamos inseridos na América, ainda rejeitamos o livre trânsito dos demais habitantes do continente em nossas fronteiras.

\footnotetext{
$\S$ Disponível em: https://www.jornalopcao.com.br/ultimas-noticias/ouca-entrevista-em-que-bolsonarochama-refugiados-de-escoria-e-sugere-infarto-a-dilma-46313/. Acesso em: 15 de dezembro de 2018.

** Disponível em: https://www.bbc.com/portuguese/noticias/2015/12/151217_brasil_latinos_tg. Acesso em: 15 de dezembro de 2018.
} 


\section{2. $O$ caso da Venezuela}

Em 2018, o Brasil teve que lidar com uma situação complicada quando milhares de venezuelanos decidiram atravessar a fronteira para tentar a vida em terras brasileiras. Esse deslocamento físico é um desdobramento da situação econômica e social de um país que sofre com a fome, o endividamento, a falta de emprego e a miséria, causada, dentre outras razões, pela interferência dos Estados Unidos na economia nacional.

Em decorrência desse problema, a pacata cidade fronteiriça de Pacaraima viu afetada a normalidade e a tranquilidade dos seus dias. Situada no estado de Roraima, ela possui pouco mais de nove mil habitantes e uma tímida economia que obriga grande parte dos cidadãos a se deslocar até a capital (ou a outras cidades de maior potencial econômico) para trabalhar. Com o início do processo de chegada em massa de venezuelanos, a dinâmica de Pacaraima foi modificada. Em entrevistas aos jornais de circulação nacional, moradores chegaram a relatar que roubos e espancamentos se tornaram recorrentes após a chegada dos venezuelanos. Além disso, a precarização dos serviços públicos se tornou um problema ainda mais visível ${ }^{\dagger \dagger}$.

A presença acentuada dos estrangeiros na cidade brasileira gerou intensos conflitos identitários, de modo que, em agosto de 2018, o governo do estado chegou a ingressar com uma ação no Supremo Tribunal Federal solicitando o fechamento da fronteira com o país vizinho. Na ocasião, Michel Temer afirmou que essa obstrução territorial era ilegal.

Os conflitos na fronteira caracterizaram-se pela violência e a intolerância dos brasileiros contra o povo venezuelano. Ainda em agosto de 2018, um grupo de brasileiros ateou fogo nas roupas e nos acampamentos dos estrangeiros nas ruas de Pacaraima.

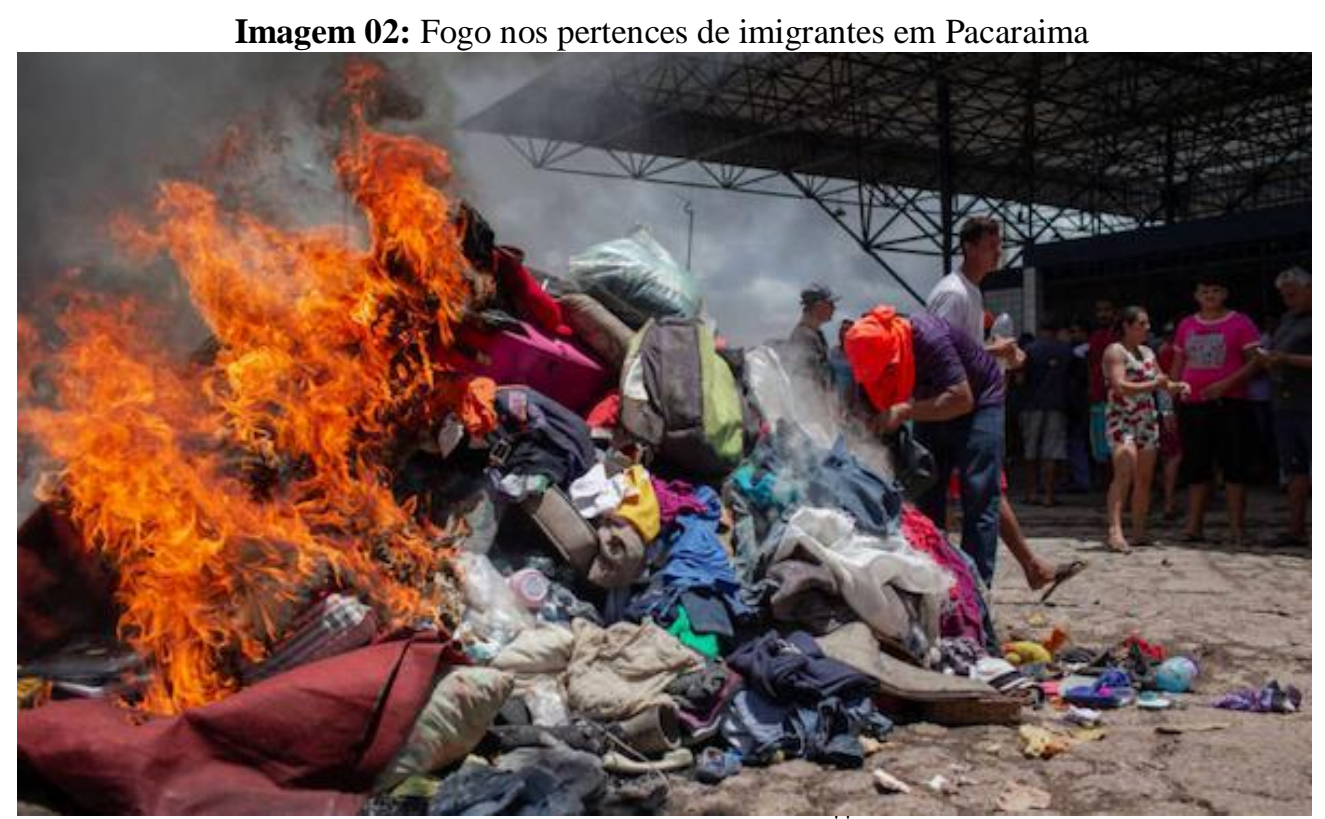

Fonte: Blog do Sakamoto

\footnotetext{
${ }^{\dagger}$ Disponível em: https://brasil.elpais.com/brasil/2018/08/17/politica/1534459908_846691.html. Acesso em: 15 de dezembro de 2018.

\# Disponível em: https://blogdosakamoto.blogosfera.uol.com.br/2018/08/19/roupas-de-refugiados-sendoqueimadas-mostram-ao-mundo-um-brasil-sem-governo/ Acesso em 18 de dezembro de 2018.
} 
A imagem circulou nas redes sociais e nos principais jornais da América Latina. O estereótipo amigável e receptivo do povo brasileiro dissipava-se com o fogo que queimava as roupas dos vizinhos caribenhos. Pela primeira vez mostramos ao mundo que não somos verdadeiramente receptivos, desconstruindo, assim, uma imagem muito difundida sobre os habitantes desta terra. Um fato que chamou a atenção no episódio foi que alguns moradores que participaram do ato cantavam o Hino Nacional, como se os atos de brutalidade fossem uma atitude patriótica, digna de reconhecimento moral e ético. A intolerância e a violência pareciam estar liberadas em nosso país.

\section{Fascismos nossos de cada dia}

Os eventos mencionados anteriormente são atravessados por discursos e práticas de cunho fascista, evidenciando uma estrutura de poder que se configura como a representação da intolerância ao diferente e, consequentemente, ao estrangeiro. Nesse sentido, recorremos às palavras de Rubens Casara, dispostas na apresentação de Como conversar com um fascista, obra escrita pela professora brasileira Marcia Tiburi, para entender o conceito de fascismo utilizado por nós:

Hoje, parece que há consenso de que existe(m) fascismos para além do fenômeno italiano ou, ainda, que o fascismo é um amálgama de significantes, um "patrimônio" de teorias, valores, princípios, estratégias e práticas à disposição de governantes ou de lideranças de ocasião (que podem, por exemplo, ser fabricadas pelos detentores do poder político ou econômico, em especial através dos meios de comunicação de massa) (CASARA, 2018, p. 12).

Por essa concepção, entende-se que o fascismo clássico italiano gerou outros tipos de práticas autoritárias em países e conjunturas diversas. Entretanto, de modo geral, aponta-se para o fascismo como um mecanismo operante que serve para a manutenção do poder econômico e político de uma classe social específica. Assim, Marcia Tiburi conceitua o sujeito fascista com os seguintes termos:

Fechado em si mesmo, o fascista não pode perceber o "comum" que há entre ele e o outro, entre "tu e eu". Ele não forma mental e emocionalmente a noção do comum, porque, para que esta noção se estabeleça, dependemos de algo que se estabelece com uma abertura ao outro. Fascista é aquela pessoa que luta contra laços sociais reais enquanto sustenta relações autoritárias, relações de dominação [...] $\mathrm{O}$ fascista usa o afeto destrutivo do ódio para cortar laços potenciais, ao mesmo tempo que sustenta, pelo ódio, a submissão do outro. Como personalidade autoritária, ele luta contra o amor e as formas de prazer em geral. Um fascista não abraça. Ele não recebe (TIBURI, 2018, p. 24).

O fascista é incapaz de realizar um movimento de alteridade, dado que este processo de reconhecimento só é possível quando reconhecemos a existência do outro nas suas diferenças e singularidades. O que aconteceu em Pacaraima pode ser considerado um ato fascista por diversos motivos. Primeiramente pela incapacidade de 
perceber a humanidade no outro: os pertences dos venezuelanos foram queimados como se não possuíssem donos. O segundo motivo diz respeito à impossibilidade de nos colocarmos no lugar do outro: como reagiríamos se, do outro lado da fronteira, nossos bens materiais fossem queimados? O terceiro motivo indica que os cidadãos de Pacaraima utilizaram a força do ódio como mecanismo de submissão e de poder: era necessário evidenciar que aquele território não pertencia aos venezuelanos: uma forma de submissão e inferiorizarão do outro.

É necessário sublinhar ainda que o fascismo representa a destruição, pois, nas palavras de Marcia Tiburi (2018, p. 30), "somos seres capazes de amar e odiar. O motivo pelo qual amamos é inversamente proporcional ao porque odiamos. No primeiro caso, construímos, no segundo, destruímos". Em Pacaraima, os brasileiros destruíram não só as roupas e pertences dos venezuelanos. Destruíram também sonhos, histórias de vida. A dignidade humana.

\section{Pode a literatura latino-americana nos ensinar a respeitar os imigrantes?}

A literatura latino-americana tem uma função primordial no processo de integração regional da América Latina. Parte da proposta da Biblioteca Ayacucho, por exemplo, consiste na democratização do acesso à leitura literária de autoras e autores do continente. Nesse sentido, Antonio Candido e Angel Rama incentivaram o intercâmbio literário no Brasil com os países hispânicos, partindo da ideia de que era necessário conhecer a produção dos escritores vizinhos e tornar conhecida a literatura brasileira nos países de língua espanhola.

Compartilhamos a ideia de que a literatura possui uma função social na vida dos seres humanos, visto que ela é capaz de humanizar, para utilizar o termo de Antonio Candido (2004). A literatura nos humaniza porque nos coloca no lugar do outro. A literatura nos humaniza porque nos permite vivenciar um mundo e experiências novas. A literatura nos humaniza porque nos possibilita ver as diferenças e as singularidades que nos unem. Contudo, alertamos:

E, por favor, não me entendam mal, não estou dizendo aqui que a literatura possa nos salvar dos idiotas e fascistas que nos cercam. Eles vão continuar por aí, humilhando as pessoas, perseguindo os que pensam diferente deles, batendo, torturando, esmagando ossos, como sempre fizeram. A literatura não é pílula de humanização, ela é (ou pode ser) ferramenta para aqueles que se dispõem a refletir sobre o seu lugar no mundo e sobre o lugar do outro (DALCASTAGNÈ, 2018, p. 16).

É evidente que a literatura não faz milagres. A literatura não transforma fascistas em democratas, por exemplo. Os fascistas continuarão a existir, pois, dentre outras razões, eles negam o conhecimento, o saber e as artes. Regina Dalcastagnè (2018) também nos lembra de que uma das bandeiras dos atuais políticos brasileiros é a exclusão de disciplinas, como a Sociologia, a Filosofia, as Artes, a História, do conjunto de saberes obrigatórios no Ensino Médio. Não obstante, são essas as disciplinas capazes de produzir senso crítico e reflexivo. Outrossim, a literatura não faz milagres porque o fascista não tem contato com a literatura - ou quando a leitura faz parte do seu 
cotidiano, limita-se a ler apenas escritores específicos e interpretá-los de acordo com suas próprias ideologias.

Entretanto, é preciso acreditar que a literatura pode nos tornar pessoas melhores. Por isso, insistimos que a circulação de literatura latino-americana é fundamental nas escolas, nas praças, nas ruas e nos demais espaços de socialização. É necessário conhecer a América Latina para que possamos compreender a nossa identidade e o nosso lugar de fala. É preciso ler, também, uma literatura não canônica, sair da nossa zona de conforto, para conhecermos o mundo que nos cerca e do qual fazemos parte.

Recentemente, conhecemos um projeto de poesia, editado pelo Território Poético, uma organização mexicana. Em sua página na internet, encontramos a publicação de alguns poemas de imigrantes da América Central. Para esta ocasião, apresentaremos dois poemas que tratam da imigração. O primeiro intitula-se Una canción $^{\S \S}$, de autoria de Ernesto y Vicente:

\section{Una canción}

Señor quiero preguntarte ¿si lo que he vivido significa algo?

-Un hombre mutilado

-Mujeres violadas

¿En qué momento la masacre se convirtió en una aburrida noticia para la gente?

Señor, déjame ir contigo y cruzar las fronteras del mundo.

Señor aun no tengo mi visa, ni pasaporte.

Señor llévame contigo al cielo, soy un migrante, no me cobres cuota.

Señor, ayúdame.

Nuestro camino es una cacería sangrienta.

Nuestra sangre cubre las tierras mexicanas.

Nuestro destino, un secuestro y dolor para nuestras familias.

Señor aun no tengo mi visa, ni pasaporte.

Señor llévame contigo al cielo, soy un migrante, no me cobres cuota.

Señor, llévame en un tren rumbo al cielo y no me preguntes si tengo visa, no me asaltes, no me golpees solo eso te pido.

O eu-lírico inicia o poema perguntando a um senhor, possivelmente em tom de oração, se a sua vida significa algo, depois de ter visto tantos homens mutilados e tantas mulheres violentadas, sugerindo que os processos de imigração violam os direitos humanos. Bastaria pensar, por exemplo, nas centenas de violações que ocorrem todos os anos na fronteira entre o México e os Estados Unidos.

A voz do poema coloca em debate o tema da migração quando o eu-lírico pede que o senhor o deixe atravessar as fronteiras do mundo, enfatizando que ele não possui visto, nem passaporte e não pode pagar taxas de imigração. Ademais, evidencia-se o

$\S \S$ Disponível em: http://circulodepoesia.com/2013/05/antes-de-pasar-la-frontera-poesia-de-migrantescentroamericanos/. Acesso em: 15 de dezembro de 2018. 
caminho de sangue que chega a cobrir o mapa do México, devido à violência cometida pelos norte-americanos na fronteira. Por fim, o eu-lírico suplica que o interlocutor o leve ao céu, que não lhe pergunte pelo visto, que não lhe assalte e que não cometa nenhum tipo de violência, sinalizando para a naturalização e generalização da barbárie.

Nesse sentido, Una Canción ilustra as viagens em busca da realização dos sonhos, as consequentes violações realizadas contra os direitos humanos e o desejo de sobreviver que todos os indivíduos carregam durante os deslocamentos físicos pelo nosso continente.

O segundo poema, El migrante de tierra lejana ${ }^{* * *}$, escrito por Fernando, natural da Nicarágua, também coloca no centro das discussões a questão da migração e dos laços familiares que são interrompidos quando uma pessoa decide cruzar as fronteiras territoriais de seu país:

\section{El migrante de tierra lejana.}

El migrante de tierra lejana camina andante y perseverante hacía una tierra distante y añorada.

Tiene la esperanza de algún día llegar sano a la tierra prometida que cambiara su destino, un migrante lejano.

Cada migrante sufre la nostalgia de dejar a su familia, no importa cuántas lágrimas, penas y sufrimiento pase en su camino el migrante seguirá adelante con la frente en alto sin perder el horizonte de su destino.

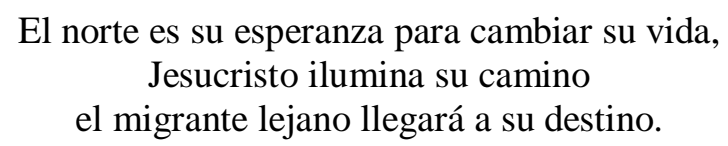

A voz lírica declara que o desejo de todo migrante é chegar com saúde na terra distante. Nesse poema, os laços familiares são tematizados quando o eu-lírico conta que o migrante vive a nostalgia de deixar a sua família, sofrendo com a ausência e a preocupação com o processo de migração. Estabelece-se uma divisão clássica dos processos de deslocamento dos cidadãos do Sul que se dirigem ao Norte do mundo em busca de uma vida melhor. Ressalta-se também a adoração a Jesus Cristo, sinalizando que a fé é a maior companhia desses indivíduos que atravessam fronteiras em busca de novas possibilidades para as suas vidas.

Evidentemente, esses poemas não foram publicados por nenhuma grande editora. São textos escritos por pessoas anônimas, desconhecidas. Mas isso não pode caracterizá-los como "não literatura" ou ter a sua qualidade estética diminuída. Pelo contrário, esses poemas comprovam que a literatura faz parte da vida humana, que a produção poética faz parte do cotidiano de pessoas comuns, de migrantes que cruzam fronteiras, de filhos, irmãos, maridos, amigos que deixam os seus parentes em lágrimas quando decidem mudar de país.

Nesse contexto, concordamos com a noção de literatura defendida por Antonio Candido (2004, p.174): "chamarei de literatura, da maneira mais ampla possível, todas as criações de toque poético, ficcional ou dramático em todos os níveis de uma sociedade". Esses poemas têm uma importância fundamental, porque nos mostram um

Disponível em: http://circulodepoesia.com/2013/05/antes-de-pasar-la-frontera-poesia-de-migrantescentroamericanos/. Acesso em: 15 de dezembro de 2018. 
lado da vida que desconhecemos. Ainda de acordo com o crítico paulista, esses poemas têm uma função particular:

A literatura pode ser um instrumento consciente de desmascaramento, pelo fato de focalizar as situações de restrição dos direitos, ou de negação deles, como a miséria, a servidão, a mutilação espiritual. Tanto num nível quanto no outro ela tem muito a ver com a luta pelos direitos humano (CANDIDO, 2004, p. 186).

Então, o eu-lírico nos dois poemas aqui analisados externalizam os problemas enfrentados pelos imigrantes, ao mesmo tempo em que denunciam a barbárie aos leitores. Essa denúncia ao autoritarismo, à violência e à violação aos direitos humanos desses cidadãos é apresentada de forma enfática e com alto teor emocional.

Dito isso, com a leitura desses poemas justificamos o título desse artigo. Pode, então, a literatura latino-americana nos ensinar a respeitar os imigrantes? Pode a literatura nos fazer vivenciar experiências de vida que não fazem parte da nossa realidade? Estamos certos que sim, a literatura pode nos transformar, pode nos tornar pessoas melhores. Contudo, é necessário estar aberto ao novo, ao diferente. A leitura literária, sem predisposição para a reflexão crítica sobre o mundo e, consequentemente, para a mudanças de discursos e atitudes, não é capaz de modificar um ser humano. Por isso, a predisposição para a reflexão e para a mudança é fundamental.

Regina Dalcastagnè $(2018$, p. 18) afirma que "a literatura é um modo de se refletir sobre o mundo, mas é também um modo de se inserir nele". Com isso, entendemos que a reflexão sobre o mundo só é possível quando estamos dispostos a nos inserir nesse mundo. Trata-se aqui do mundo marginal, dos pobres, dos favelados, das mulheres, dos negros, dos LGBT, das donas de casas. Pode não parecer, mas essas pessoas têm muito que nos ensinar:

Pensem no senhor que conserta sua geladeira, no rapaz que corta seu cabelo, na sua empregada doméstica - pessoas que certamente têm muitas histórias para contar. Agora colem o retrato deles na orelha de um livro, coloquem seus nomes em uma bela capa, pensem neles como escritores. A imagem não combina, simplesmente porque não é esse o retrato que estamos acostumados a ver, não é esse o retrato que muitos defensores da Língua e da Literatura (tudo com L maiúsculo, é claro) querem ver. Afinal, nos dizem eles, essas pessoas têm pouca educação formal, pouco domínio da língua portuguesa, pouca experiência de leitura, pouco tempo para se dedicar à escrita (DALCASTAGNÈ, 2012, p. 08).

É preciso ler literatura latino-americana como um compromisso com o mundo em que vivemos. É urgente nos inserir no mundo do outro, porque apenas o diálogo, a vivência, a experiência com o diferente é capaz de nos tornar pessoas melhores. 


\section{Encaminhamentos finais}

O caso do menino Aylan Kurdi mostrou que o Brasil é um país onde a solidariedade é seletiva. Parece que escolhemos quando e com quem seremos solidários. $\mathrm{O}$ caso do garoto sírio-curdo nos mobilizou. $\mathrm{O}$ caso dos cidadãos venezuelanos, não. Muito pelo contrário. Ateamos fogo em seus pertences, nas suas histórias, nos seus sonhos.

Não podemos afirmar que há um único culpado para o ocorrido em Pacaraima. Mas é necessário recordar que um dos desdobramentos do impedimento contra a agora ex-presidenta Dilma Rousseff e das eleições de Jair Bolsonaro é a legalização da intolerância. No momento em que elegemos um presidente que homenageia um dos mais cruéis torturadores da época da ditadura, o coronel Carlos Alberto Brilhante Ustra, oficializamos a intolerância como um mecanismo de poder governamental. Não obstante, uma das maiores bandeiras da campanha de Jair Bolsonaro é o armamento da população. Segundo ele, é preciso permitir que o cidadão de bem (sic) possa se defender dos marginais (sic), afinal, no Brasil, os direitos humanos servem apenas para proteger bandidos (sic).

É necessário também assumir as nossas ações. $\mathrm{O}$ fogo que consumiu as roupas dos venezuelanos no território brasileiro é resultado de manifestações discursivas de Jair Bolsonaro. Se o representante máximo desse país menospreza e inferioriza determinados povos, dá-se o aval para que um grupo de cidadãos se ache no direito de se proteger dos imigrantes venezuelanos, ateando fogo, ao som do Hino Nacional.

Outrossim, pensamos que é fundamental rever o projeto da Biblioteca Ayacucho. É urgente ler literatura latino-americana nas escolas e nos demais espaços não-formais de ensino, porque a leitura de escritoras e escritores nascidos na América Latina nos permite conhecer a nossa própria história. Por isso, acreditamos que o processo de integração regional só será possível quando os governos brasileiros e dos países vizinhos priorizarem o diálogo intercultural, através do ensino de línguas e literaturas latino-americanas, iniciando, então, um projeto continental baseado na leitura literária, na educação e na valorização das identidades locais.

\section{Referências}

CASARA, R. S. Apresentação. In: TIBURI, M. Como conversar com um fascista. Rio de Janeiro: Record, 2018.

CANDIDO, A. O direito à literatura. In: Vários escritos. São Paulo; Rio de Janeiro: Duas cidades; Ouro sobre azul, 2004.

DALCASTAGNÈ, R. Literatura brasileira contemporânea: um território contestado. Rio de Janeiro: EdUERJ, 2012.

O que o golpe quer calar: literatura e política no Brasil hoje. In: Anuário de literatura (UFSC), 2018. Disponível em: <https://periodicos.ufsc.br/index.php/literatura/article/view/2175-7917.2018v23n2p13> Acesso em: 16 de janeiro de 2019.

FUKS, J. A resistência. São Paulo: Companhia das Letras, 2015. 
TIBURI, M. Como conversar com um fascista. Rio de Janeiro: Record, 2018.

Recebido em 12 de janeiro de 2019

Aceito em 14 de abril de 2019 